\title{
Implementing Knowledge Management in School Environment: Teachers' Perception
}

\author{
Kai Wing Chu* \\ CCC Heep Woh College \\ 171, Po Kong Village Road, Tze Wan Shan, Kowloon, Hong Kong \\ E-mail: chukwalex@yahoo.com.hk
}

\section{Minhong Wang}

Faculty of Education

The University of Hong Kong, Hong Kong

E-mail: magwang@hku.hk

\author{
Allan H.K. Yuen \\ Faculty of Education \\ The University of Hong Kong, Hong Kong \\ E-mail: hkyuen@hkucc.hku.hk \\ *Corresponding author
}

\begin{abstract}
Knowledge Management (KM) can be used as an alternative strategy by schools to help teachers equipped with relevant skills to face the challenges to improve performance as its uses in commercial sectors. However, little research has been undertaken on how $\mathrm{KM}$ can be applied to school environment. To put KM into action, it is crucial to understand teachers' perception of KM at the outset. The study was carried out in a typical Hong Kong secondary school. Interviews, based on relevant KM models, were conducted to understand teachers' perception of KM. We found that knowledge sharing, people, culture and knowledge storage with IT support were regarded as important from the interviewees' points of view. Most interviewees might accept that KM can help improve their practice but it needs the support of various dimensions such as people, culture, IT and management. The findings may provide insights for KM implementation in the school.
\end{abstract}

Keywords: Knowledge Management; Teacher Learning; Teacher Perception

Biographical notes: Kai Wing CHU is a principal of a Hong Kong secondary school. He is currently pursuing Doctor of Education in the University of Hong Kong. His research interest is implementing Knowledge Management in schools for teacher professional development.

Minhong Wang is an Assistant Professor in the Faculty of Education, The University of Hong Kong. She received her Ph.D. in Information Systems from City University of Hong Kong in 2005. Her current research interests include elearning, Web-based training and professional development, knowledge management, complex process management, and information systems. She has published papers in Information \& Management, Computers \& Education, IEEE Transactions on Education, Educational Technology \& Society, Expert 
Systems with Applications, Knowledge-based Systems, Journal of Knowledge Management, among others. She is the Editor-in-Chief of Knowledge Management \& E-Learning: an International Journal (KM\&EL), and serves on the Editorial Board of several international journals.

Allan H.K. YUEN is Associate Professor of the Faculty of Education of the University of Hong Kong. His research interests are evaluative and comparative studies on information technology in education, learning community and knowledge building, technology acceptance and educational change, and mathematics and computer studies education.

\section{Introduction}

Organizations are starting to understand and appreciate knowledge as the most valued asset in the emerging competitive environment (Bailey \& Clarke 2000 ; Nonaka \& Takeuchi 1995). Davenport and Prusak (1997) defined knowledge enterprise from the primary activities involved. They identified activities such as acquisition, creation, packaging or application of knowledge. The objective of Knowledge Management (KM) is to improve the quality of the contributions people make to their organizations by helping people to make sense of the context within which the organization exists, to take responsibility, to cooperate and share what they know and learn, and to effectively challenge, negotiate and learn from others. Organizations have the potential to learn and that new knowledge may be effectively incorporated into specific practices, so that the knowledge is accessible when needed. Schools, like most organizations, should learn and gain knowledge so as to improve decision making and innovation especially in the age of increased external and internal pressures for change and improvement. KM can be used as a strategy by schools to improve competitive performance. Zhao (2010) points out that school KM can facilitate acquisition, sharing and application of teacher knowledge in school so as to better manage and apply schools' tangible and intangible knowledge assets, especially the professional knowledge, experiences and competencies of teachers. Several recent studies have explicitly called for new research to focus on KM in schools (Chu, Wang, Zhou \& Yuen, 2009; Ge et al., 2006; Wang \& Jia, 2005, Zhao, 2010). In Hong Kong, there have been very few empirical studies that shed light on this topic. In this paper, KM at organizational level will be the focus. This study is the starting point to look for insight into the design and implementation of KM initiatives at organization level and minimize the obstacles in KM practice in a secondary school.

The rest of the paper is organized as follows. Section 2 gives a brief introduction of $\mathrm{KM}$ and discusses the need for KM in schools as well as the key factors of KM implementation, which were used to design the interview questions for investigating teacher perception of KM in this study. In Section 3, the motivation of the study is addressed and the research questions are presented. Section 4 provides details of the interviews conducted in the selected school. The results of the study are presented in Section 5. Finally, Section 6 concludes the study and gives insight into and suggestions for further work. 


\section{Related Work}

\subsection{Knowledge Management (KM) in Schools}

KM is not a new concept. Barron (2000) defines KM as "an integrated, systematic approach to identifying, managing and sharing all of an enterprise's information assets, including databases, documents, policies and procedures, as well as previously unarticulated expertise and experience held by individual workers." According to Zack (1999), a typical KM process includes five stages: acquisition, refining, storage and retrieval, distribution and presentation. Nevertheless, the nature of knowledge is complex; many people try to identify what knowledge is from different perspectives. There are two common ways to distinguish knowledge. Some scholars, like Kogut and Zander (1996), distinguish between know-what and know-how (practical knowledge) while others, like Nonaka (1994), prefer to use the distinction between tacit and explicit knowledge based on Polanyi's (1967) theory. In general, tacit knowledge is hard to articulate and transfer, and has been linked with know-how; explicit knowledge is relatively easy to articulate and codify, and has been linked with know-what. A good KM system must treat all sorts of knowledge, from know-what to know-how, and from tacit to explicit. This is the greatest difficulty for the implementation of a KM project. Meanwhile, the complexity of what knowledge means has led to different approaches to managing knowledge.

In a climate of increased external and internal pressures for improvement, the information needs of school teachers and administrators have never been greater, yet the perils of information overload are real. Schools, like most organizations, should learn and gain knowledge so as to enhance teacher competency. There are many sorts of knowledge, which need to be managed in schools. Cochran-Smith and Lytle (1999) provide a valuable distinction in the types of knowledge that inform practice: knowledge of practice, or information about student performance, and knowledge for practice, or information about best practice. Teachers develop and acquire different kinds of knowledge in school where KM should be applied to facilitate managing teachers' knowledge.

KM can also be used as an alternative strategy by schools to improve competitive performance. Petrides and Nodine (2003) consider broadly that knowledge management in education can be thought of as a framework or an approach that enables people within an organization to develop a set of practices to collect information and knowledge mentioned above and share what they know, leading to action that improves services and outcomes. In seeking to balance an organization's information culture and its technology culture, KM brings together three core organizational resources - people, processes and technologies- to enable the organization to use and share information and knowledge more effectively. For people, organizations should promote policies and practices to help them share and manage knowledge. KM builds upon collegial and professional teamwork by actively engaging people at many organizational levels in sharing with others what they know, and what they are learning. For processes, Petrides and Nodine (2003) reminded us that formal and informal administrative procedures, curriculum development processes, information sharing patterns, information silos, salary incentives, award schemes and many other work practices affect information flow within every organization. KM initiatives help to establish robust processes that enable people to get the information they need when they need it, as well as to share it with others who may benefit from it. KM can help to promote those processes that lead to a more informed decision making. For technologies, Petrides \& Nodine (2003) state that it is the most 
effective platform for target groups to access and exchange useful information across departments. Therefore, KM can be used to better manage knowledge for schools not only by building up people networks but by also enriching knowledge in school communities by processes and technologies to improve school's competitive performance.

\subsection{Key Factors of Knowledge Management}

The study is based on the KM framework of Rodrigues and Pai (2005). Developing a suitable KM strategy is the key element of KM implementation. The framework advocates a variety of KM strategies as applied to different settings. In order to develop a suitable KM strategy for schools, we need to identify the key factors or variables of KM. The framework of Rodrigues and Pai (2005) was adopted. Rodrigues and Pai (2005) list eight key factors. The eight dimensions are listed as follows: -

Table 1. Key Factors of KM Implementation (Rodrigues \& Pai, 2005)

\begin{tabular}{|c|c|}
\hline Key Dimensions & Descriptions \\
\hline Leadership and Support & $\begin{array}{l}\text { management team's support of an organization's KM } \\
\text { activities. }\end{array}$ \\
\hline $\begin{array}{l}\text { Technology and } \\
\text { Infrastructure }\end{array}$ & $\begin{array}{l}\text { effectiveness of the organization's IT infrastructure and the } \\
\text { appropriation of an organization's technology utilization }\end{array}$ \\
\hline Knowledge Creation & knowledge creation in the workplace \\
\hline $\begin{array}{l}\text { Acquisition and } \\
\text { Learning }\end{array}$ & $\begin{array}{l}\text { methods to improve organization member's knowledge } \\
\text { searching and learning }\end{array}$ \\
\hline $\begin{array}{l}\text { Dissemination and } \\
\text { Transfer }\end{array}$ & $\begin{array}{l}\text { enablers and facilitations of transferring knowledge and } \\
\text { information within the organization }\end{array}$ \\
\hline $\begin{array}{l}\text { Application and } \\
\text { Exploitation }\end{array}$ & $\begin{array}{l}\text { employee's attitudes and requirements for applying knowledge } \\
\text { and putting it into practice }\end{array}$ \\
\hline People Competency & $\begin{array}{l}\text { effects of employees' personal skills and competencies } \\
\text { regarding handling KM }\end{array}$ \\
\hline Sharing Culture & $\begin{array}{l}\text { enablers and facilitations of building positive culture for } \\
\text { knowledge-sharing }\end{array}$ \\
\hline
\end{tabular}

These eight dimensions include most typical KM enablers and activators. This framework was developed and applied in an educational institution to measure KM performance. We adopted this framework as the theoretical basis of our study to investigate the key factors of $\mathrm{KM}$ implementation in schools.

\section{Reasons for the Study}

This study focused on teacher's perception of KM implementation in schools from an organizational perspective. School teachers' understanding and expectations of KM in the school environment were investigated. The motivation of the study includes the following three aspects: 
Firstly, collecting data regarding employees' perception of KM is necessary preparation for any KM practice. In the KM framework according to Wiig (1999), the initial step of a KM project should be "Survey and map the knowledge landscape" (pp. 36). However, some researchers focus on the measurement of an organization's deposit of knowledge and the characteristics of that knowledge (tacit/explicit) (Boisot, MacMillan, \& Han, 2007). They tend to ignore the employees' opinion on the way to implementing KM. This, in many cases, will cause the failure of a KM project (McCampbell, Clare, \& Gitters, 1999). Knowing teachers' perceptions and opinions about KM factors is therefore an important precondition for the success of a KM project in schools. In this study, interviews to collect and understand teacher's perception of KM implementation were conducted.

Secondly, this study continued the previous study (Chu et al., 2009) of investigating teacher's perception of KM using a survey instrument developed by Rodrigues and Pai (2005). The result showed that "Leadership", "Interpersonal Trust", and "Management Trust" were regarded as the three most important factors of KM implementation. The aim of this study is to further examine teacher's perception of implementing KM in depth.

Thirdly, although KM technology is now mature enough to be applied in practice across sectors, the integration of KM and education administration is still a newborn phenomenon. Most KM researchers do not have a background in education and they always neglect the gap between KM and KM in schools. We claim that a KM project in a school needs knowledge and suggestions from the teachers, who are experts in education and pedagogy. Through this study, we want to explore teachers' perception of KM in schools in terms of KM implementation.

Therefore, the research questions of the study are:

1. What are teachers' understanding of Knowledge Management and its benefits to school and themselves?

2. What are teachers concerns about KM implementation?

3. What pre-requisites do teachers expect for KM implementation?

4. What benefits do teachers anticipate from KM implementation?

\section{Methodology}

\subsection{Background}

This study is treated as the first step of an action research in a selected secondary school. This is a typical secondary school in Hong Kong. Although the school has already installed an Intranet system with efficient and user-friendly functions including e-mail, broadcast, uploading and downloading document, storing teaching and learning materials, monitoring student progress, and an e-learning platform for staff and students, little knowledge management has been initiated in the school. Besides, several servers have been installed for sharing files among teachers, and collaboration among teachers, such as "Lesson Study" for co-planning and co-evaluating the lessons in various subjects in the school have been launched for several years. 


\subsection{Research Procedure}

Because teachers are key players in organization knowledge creation (Nonaka \& Takeuchi, 1995), they are the core subjects in this study, and understanding their perception of KM is the focus of this research. All teachers were invited to participate in a voluntary interview by means of returning a letter of consent to the researcher. Most of the teachers (56 out of 62) were willing to participate. 33 teachers were randomly selected from the teachers who were interested. Two groups of external interviewers (each consisting of one main interviewer and one assistant) were recruited and allocated to conduct interviews with standard interview questions and protocols. Each interview lasted for about 20-30 minutes with voice recording under participants' agreement. All interviewees' answers were summarized, recorded and translated from Cantonese into English in the appendix. Back translation of the results has been done to verify their validity. Interviewees' answers have been analyzed to identify the main points or themes occurring in the process. Interviewees were identified using codes like A1 or B12, with letter $\mathrm{A}$ or $\mathrm{B}$ representing the interview groups and the numbers representing the number of persons in the respective group.

Several measures were adopted to minimize any psychological stress and discomfort in the process. Firstly, the primary researcher did not monitor or supervise the interview process. Secondly, teachers participating in the project could withdraw at any time they liked. Furthermore, if any teachers did not feel comfortable or felt worry about the interview, they would be given the interview questions by intranet email one evening before. Interviewers tried their best to keep teachers' anonymity. The process of the interviews had been approved by the supervisors and HKU research ethic committee before the interviews started.

\subsection{Research Framework}

Interview questions were designed according to the framework adopted from Rodrigues and Pai's (2005) the eight dimensions KM enablers and activators model. The relationship between the interview questions, research questions and framework are listed below:

Table 2. Relationship between interview questions, research questions and framework of conceptualization

\begin{tabular}{|c|c|c|}
\hline Interview Questions & $\begin{array}{l}\text { Research } \\
\text { Questions } \\
\text { Addressed }\end{array}$ & $\begin{array}{l}\text { Relations to the Framework of } \\
\text { this Study }\end{array}$ \\
\hline $\begin{array}{l}a \text { Understanding of KM: } \\
\text { Have you heard about } \\
\text { knowledge management? } \\
\text { What's your understanding of } \\
\text { KM? }\end{array}$ & $\begin{array}{l}\text { What is teachers' } \\
\text { understanding of } \\
\text { Knowledge } \\
\text { Management }\end{array}$ & $\begin{array}{l}\text { understand teachers' conception } \\
\text { of KM. Do teachers know the } \\
\text { components of KM } \\
\text { implementation, such as } \\
\text { "Knowledge Creation", } \\
\text { "Acquisition and Learning", } \\
\text { "Dissemination and Transfer", } \\
\text { "Application and Exploitation"? }\end{array}$ \\
\hline $\begin{array}{c}b \cdot \text { Concerns about KM } \\
\text { What are your feelings about } \\
\text { the implementation of } \\
\text { knowledge management in }\end{array}$ & $\begin{array}{l}\text { What are } \\
\text { teachers } \\
\text { concerns of } \mathrm{KM}\end{array}$ & $\begin{array}{l}\text { investigate teachers' self } \\
\text { confidence, self efficacy, self } \\
\text { perceived competencies, attitude } \\
\text { or feeling about the eight KM }\end{array}$ \\
\hline
\end{tabular}




\begin{tabular}{|c|c|c|}
\hline $\begin{array}{l}\text { your school? What are your } \\
\text { concerns? }\end{array}$ & implementation & dimensions. \\
\hline $\begin{array}{l}c \text { Prerequisites for Support of } \\
\text { KM : } \\
\text { To put KM into action, we } \\
\text { need support from different } \\
\text { quarters, such as people, } \\
\text { culture, management and IT. } \\
\text { What issues do you think are } \\
\text { important for putting KM into } \\
\text { action in your school, and } \\
\text { why are they important? }\end{array}$ & $\begin{array}{l}\text { What pre- } \\
\text { requisite } \\
\text { teachers expect } \\
\text { for KM } \\
\text { implementation }\end{array}$ & $\begin{array}{l}\text { understand teachers' perceived } \\
\text { importance of KM components } \\
\text { in implementation in future, such } \\
\text { as "Leadership and Support", } \\
\text { "Technology and Infrastructure", } \\
\text { "People Competency", and } \\
\text { "Sharing Culture" or their } \\
\text { perceived readiness of these } \\
\text { components above at that time. }\end{array}$ \\
\hline $\begin{array}{l}d \cdot \text { Expected Outcomes of } \\
K M \\
\text { What do you expect to } \\
\text { achieve from promoting and } \\
\text { implementing KM in your } \\
\text { school? }\end{array}$ & $\begin{array}{l}\text { What benefits } \\
\text { teachers } \\
\text { anticipated for } \\
\text { KM } \\
\text { implementation }\end{array}$ & $\begin{array}{l}\text { study teachers' attitude and } \\
\text { feelings about KM, which can in } \\
\text { turn affect "People } \\
\text { Competency", and "Sharing } \\
\text { Culture" and reflect their } \\
\text { potential involvement in KM } \\
\text { implementation in school. }\end{array}$ \\
\hline
\end{tabular}

\section{Results}

Common patterns for analysis were identified in the interviewees' responses.

\subsection{Understanding of $\mathrm{KM}$}

Most teachers did know the meaning of Knowledge Management (KM), although their scope of KM was not so broad and they did not know too much about KM components. They mentioned some main points of KM as follows:

Table 3. Analysis of The Interviewee Response of the question: 'Have you heard about knowledge management? What's your understanding of KM?'

\begin{tabular}{ll}
\hline Main points mentioned by interviewee & Interviewee \\
\hline Knowledge sharing & $\mathrm{A} 3, \mathrm{~A} 4, \mathrm{~B} 9, \mathrm{~B} 10, \mathrm{~B} 14, \mathrm{~B} 18$ \\
\hline Knowledge storage & $\mathrm{A} 8, \mathrm{~B} 16, \mathrm{~B} 17, \mathrm{~B} 18$ \\
\hline Knowledge transfer & $\mathrm{B} 6, \mathrm{~B} 13$ \\
\hline Conversion of Tacit Knowledge to Explicit Knowledge & $\mathrm{A} 6, \mathrm{~B} 12$ \\
\hline Knowledge Access & $\mathrm{A} 8$ \\
\hline Knowledge Categorization & $\mathrm{A} 1$ \\
\hline Knowledge Searching & $\mathrm{B} 11$ \\
\hline Protect knowledge & $\mathrm{A} 12$ \\
\hline Combine knowledge & $\mathrm{A} 11$ \\
\hline Update knowledge & $\mathrm{B} 8$ \\
\hline
\end{tabular}


Most interviewees regarded the most important function of $\mathrm{KM}$ as the sharing and storage of knowledge. They were aware that knowledge could be an asset of an organization. This knowledge had its value and should be stored, shared and even protected to prevent the loss of knowledge from the organization. They also realised that knowledge should be converted from tacit knowledge to explicit knowledge, so that it could be readily shared or transferred within the organization. This can be concluded say that they commended "Dissemination and Transfer" were most prominent in KM. Some interviewees further thought about the reusability of the knowledge; they thought that the knowledge stored in the school should also be categorized, so that the searching of useful information and its retrieval could be easily achieved. Furthermore, knowledge also needed to be combined and updated for better use. Their ideas indicated that they knew the need of "Application and Exploitation" in KM. However, the other KM components, such as "Knowledge Creation" and "Acquisition and Learning" seemed to be neglected.

\subsection{Concerns for Implementing $\mathrm{KM}$}

Most interviewees were concerned about the implementation of Knowledge Management $(\mathrm{KM})$ in school. They mentioned some main points of KM implementation as follows:

Table 4. Analysis of The Interviewee Response of the question: 'What are your feelings about the implementation of knowledge management in your school? What are your concerns?'

\begin{tabular}{ll}
\hline Main points mentioned by interviewee & Interviewee \\
\hline Knowledge sharing & $\mathrm{A} 2, \mathrm{~A} 4, \mathrm{~A} 7, \mathrm{~A} 8, \mathrm{~A} 9, \mathrm{~A} 11, \mathrm{~A} 15, \mathrm{~B} 1$, \\
& $\mathrm{B} 2,, \mathrm{~B} 3, \mathrm{~B} 4, \mathrm{~B} 5, \mathrm{~B} 7, \mathrm{~B} 8, \mathrm{~B} 9, \mathrm{~B} 10$, \\
& $\mathrm{B} 11, \mathrm{~B} 12, \mathrm{~B} 16, \mathrm{~B} 17$ \\
\hline Knowledge transfer & $\mathrm{A} 5, \mathrm{~A} 6$, \\
\hline Knowledge capture and acquisition & $\mathrm{A} 12, \mathrm{~A} 13$ \\
\hline IT support & $\mathrm{A} 3, \mathrm{~A} 6, \mathrm{~A} 12$ \\
\hline Support to Novice teacher & $\mathrm{A} 7, \mathrm{~A} 9$ \\
\hline Building up a knowledge base & $\mathrm{A} 7, \mathrm{~A} 10, \mathrm{~B} 9$ \\
\hline Culture & $\mathrm{A} 2, \mathrm{~B} 11, \mathrm{~B} 17$ \\
\hline Mutual Support & $\mathrm{B} 1$ \\
\hline Retention or loss of knowledge & $\mathrm{A} 5$ \\
\hline
\end{tabular}

Most interviewees emphasized there should be knowledge sharing when Knowledge Management (KM) would be implemented in school. Interviewees expected that teachers could share their experience in class teacher's work (A6), teaching method or best practice (A7), teaching experience (B5 and B10) and student personal information (B2). They seemed to demonstrate that they had self confidence and self efficacy in sharing experience. Some interviewees thought that sharing could help them perform their job efficiently because teachers could use other teachers' experience (B7). They reflected positive attitudes or feelings towards knowledge sharing. Some interviewees were aware that the materials shared might not be useful to all teachers (A15 and B16). Some interviewees were also aware that teachers might not be willing to share their experience with others (A4) or teachers had no time to share (B10). They also expressed worries or negative feelings or attitudes towards knowledge sharing. 
Interviewees noted the need of sharing, transfer and retention of knowledge, otherwise knowledge would be lost when some teachers left the school (A5 and A6).

From the interviewees' perspective, IT support was also important to promote the implementation of KM (A3, A6, A12). IT facilities should be strengthened, especially the forum and knowledge repository (storage space) (A7, A10, B9) to set up a platform for sharing and storing of knowledge. Although the school personnel were commonly using the intranet system, it was mostly used to send and receive emails and assignments. Its usage could be exploited. Moreover, the system should be well designed to be user friendly and conveniently and commonly used in daily practice. Culture was also regarded as important in the implementation of $\mathrm{KM}$ (A2, B11, B17). The interviewees mentioned learning culture (A2), consensus (B11) and sharing culture (B17). A culture with a common positive attitude to learning and sharing was thought to be essential to the implementation of KM. These opinions showed their feelings about inadequate conditions of IT support and culture for KM. School should address their needs by improvement in IT support and culture.

Some interviewees thought that KM could help experienced teachers transfer their experience to novice teachers, especially teaching methods, best practice and the knowledge that could not be easily learned from courses, such as skills in managing students' behaviour (A7 and A9). The need for mentoring was expressed.

Finally, one interviewee expressed that knowledge sharing could also bring mutual support to teachers (B1). It showed the positive elements of KM.

The points mentioned above were those offered by interviewees about the implementation of KM in this school.

\subsection{Prerequisites for Implementing KM}

Most interviewees mentioned the prerequisites for support of implementation of Knowledge Management (KM) in school. They mentioned some main prerequisites for support of KM implementation as follows:

Table 5. Analysis of The Interviewee Response of the question: 'To put KM into action, we need support from different quarters, such as people, culture, management and IT (explain if possible). What are the issues you think more important for putting KM into action in your school, and why are they important?'

\begin{tabular}{ll}
\hline Main points mentioned by interviewee & Interviewee \\
\hline All (people, culture, management and IT) & $\mathrm{A} 2, \mathrm{~A} 3, \mathrm{~A} 13, \mathrm{~B} 11$ \\
\hline People & $\mathrm{A} 7, \mathrm{~A} 8, \mathrm{~A} 9, \mathrm{~A} 10, \mathrm{~A} 11, \mathrm{~A} 12, \mathrm{~B} 1$, \\
& $\mathrm{B} 2, \mathrm{~B} 3, \mathrm{~B} 4, \mathrm{~B} 5, \mathrm{~B} 13, \mathrm{~B} 14$ \\
\hline Culture & $\mathrm{A} 6, \mathrm{~A} 15, \mathrm{~B} 6, \mathrm{~B} 7, \mathrm{~B} 8, \mathrm{~B} 12, \mathrm{~B} 15$, \\
& $\mathrm{B} 16, \mathrm{~B} 17, \mathrm{~B} 18$ \\
\hline IT support & $\mathrm{A} 4, \mathrm{~A} 5, \mathrm{~A} 15, \mathrm{~B} 10$ \\
\hline Management & $\mathrm{A} 14$ \\
\hline
\end{tabular}

Some interviewees thought that people, culture, management and IT were all important for Knowledge Management (KM) to be implemented successfully in schools (A2, A3, A13, B11). However, out of the four conditions of KM implementation, most of 
the interviewees regarded "people" (A7, A8, A9, A10, A11, A12, B1, B2, B3, B4, B5, B13, B14) and "culture" (A6, A15, B6, B7, B8, B12, B15, B16, B17, B18) as the two most important conditions of KM implementation. These two conditions were quite related and mutually dependent. Therefore, if the school personnel would like to implement KM in school, they should firstly change the perceptions or attitudes of people and the culture of the organization. Interviewees reflected that they needed communication and interaction to understand the benefits of KM, and they pointed out that the school personnel needed to convince staff to be involved in KM. They noted that they also needed trust to encourage knowledge sharing and coordination is required to balance the conflict of interests. Interviewees concluded that a culture of willingness to share their own knowledge and trusting each other are very important for implementing $\mathrm{KM}$. Some interviewees reflected that at present the culture to allow knowledge sharing in the researched school at present has not yet been established and they understood that such culture would need considerable time to be inculcated. The opinions above showed the importance and readiness of KM components of "People Competency" and "Sharing Culture", as well as "Leadership and Support".

IT support was also regarded by interviewees as a condition for KM implementation, such as "categorization of knowledge" and "storage and retrieval" (A4, A5, A15, B10). Some interviewees also complained that the existing system failed to serve teachers neither for knowledge sharing nor for daily practice, and it should be upgraded. The opinions can be regarded as the importance of another KM components "Technology and Infrastructure".

Finally, management support was also regarded as necessary for implementation of KM (A14) but not as important as other conditions. The interviewees pointed out that leadership and top management support would empower staff to implement KM actively. This belonged to the KM components of "Leadership and Support".

\subsection{Expected Outcomes of KM}

Most interviewees expressed the expected outcomes of Knowledge Management (KM) in school. They mentioned some main expected outcomes of KM implementation as follows:

Table 6. Analysis of The Interviewee Response of the question: 'What do you expect to achieve from promoting and implementing KM in your school?'

\begin{tabular}{ll}
\hline Main points mentioned by interviewee & Interviewee \\
\hline Learning of experience from others & A1, A4, A6, A7, A9, A11, A12, B5, \\
& B7, B15 \\
\hline Sharing Knowledge & A4, A5, B11, B12, B14, B17, B18 \\
\hline Time saving, efficient work & A4, A5, A10, A13, A15, B17 \\
\hline Getting useful information & A8, A15, B1, B2, B8, B10 \\
\hline Benefits to students & A3, A4, A14, B13 \\
\hline Self enhancement & A2, B4 \\
\hline Sharing Culture & A5, B9 \\
\hline Problems Solving & A7 \\
\hline Enhancing Harmony and Communication & A3 \\
\hline Materials storage for future use & B4, \\
\hline
\end{tabular}


Most interviewees emphasized knowledge sharing when Knowledge Management (KM) would be implemented in school. Most interviewees noted that KM could help them learn experience from others (A1, A4, A6, A7, A9, A11, A12, B5, B7, B15) and acquire shared knowledge (A4, A5, B11, B12, B14, B17, B18). They felt that KM could allow them to acquire experience and knowledge to improve their practice. They would be more efficient and competent in their practice (A4, A5, A10, A13, A15, B17), and their teaching performance would improve. They felt that it could also help them get information they needed (A8, A15, B1, B2, B8, B10). This could make their practice beneficial to students (A3, A4, A14, B13). Interviewees thought that teachers would also gain self enhancement from the knowledge they acquired (A2, B4). They also felt that a sharing culture would be built up (A5, B9) to facilitate further knowledge sharing. Some interviewees pointed out that KM could help problem solving (A7), enhancing harmony and communication and building up storage of material for future use (B4). They mostly thought that KM could empower their competency to enhance their productivity. They seemed to express their eagerness and positive attitude towards KM. It may be advantageous to develop "People Competency" and "Sharing Culture" in KM implementation in future.

\section{Conclusion and Discussion}

As an initial investigation of KM implementation in a selected secondary school, this study investigated teachers' perceptions of KM implementation via interviews. Most existing research has investigated KM in schools from the point of view of experts or even outsiders, and few studies have investigated teachers as end user's of KM implementation. Therefore, the results might help us understand KM in the school environment from the participants' viewpoint. This study might also serve as a diagnostic step in further study of KM in schools, i.e., developing a better understanding of key problems to be dealt with in KM implementation in schools. Based on the literature review, we designed the interview questions and conducted interviews in the school in this study. The interview involved 4 questions to study teachers' perceptions of KM implementation: Understanding of KM, Concerns of KM, Needs for Support of KM and Expected Outcomes of KM.

From the interviewees' response to the question of "Understanding of KM", we found that teachers recognized KM was important for organization to manage knowledge as an asset that can be stored, shared, transferred or transformed among members. They could know that "Dissemination and Transfer" and "Application and Exploitation" were the essential KM components, but they might have neglected the essence of other KM components such as "Knowledge Creation" and "Acquisition and Learning". Therefore, some formal and systematic training may be necessary to help teachers realize the overall picture of KM. From the results of the question of "Concerns of KM", we found that teachers did emphasize the benefits of knowledge sharing and also showed their self confidence and self efficacy in knowledge sharing in their daily practice, as well as showing their worries and drawbacks concerning KM implementation. More collaboration could be organized to provide opportunities for sharing among teachers to strengthen their confidence and positive attitudes towards KM as well as strengthening the trust among staff so as to minimize negative feelings. Teachers further pointed out that IT support and culture were also critical but inadequate to promote $\mathrm{KM}$ implementation and therefore they needed to be improved. In the part on "Prerequisites for Support of KM", IT and culture support together with people and management support, which were the key KM components: "Technology and Infrastructure", "Sharing 
Culture", "People Competency" and "Leadership and Support" were further noted for their importance in facilitating KM implementation. Among them, people and culture were most frequently mentioned among interviewees. Actually, people and culture were regarded in this study as closely related and mutually dependent conditions. Interviewees reflected that communication, interaction and trust among teachers did foster building up a community with a sharing culture in schools for KM implementation. Interviewees also expressed that the school needed to enhance the four KM components as conditions for KM implementation. For the part on "Expected Outcomes of KM", most interviewees expected that KM could help them acquire information, experience and knowledge from others to improve their practice and enhance their competence and efficiency in their work. Moreover, KM was believed to enhance the building up of a sharing culture, which emphasizes organizational problem-solving, collegiality and shared resources in school. They showed their positive attitude to KM and may welcome KM implementation in future.

In conclusion, the eight key components in the framework of the study can help us understand teacher's perceptions of KM in school. From this study, we can note that the four KM components: "Knowledge Creation", "Acquisition and Learning", "Dissemination and Transfer", "Application and Exploitation" are the Process Components of the KM components and the other four components: "Leadership and Support", "Technology and Infrastructure", "People Competency" and "Sharing Culture" are the Condition Components of the KM components. Schools need to provide training to teachers to allow them learn more about the process components, so that teachers could have better "People Competency" and "Sharing Culture". Moreover, the other Condition Components: "Leadership and Support" and "Technology and Infrastructure" should also be strengthened to facilitate KM implementation. Both Process Components and Condition Components need to be addressed in order to foster teachers' positive attitudes, feelings or perceptions towards KM and minimize those worries or other negative attitudes, feelings or perceptions and in turn facilitate KM implementation.

We have to admit that, because of the limitations of the interview, the results of this research might not be valid in other scenarios. However, the study contributed to new knowledge by examining perceptions of teachers as end users of KM implementation in a school environment. Since most other research has been performed to develop theoretical approaches, or has investigated KM implementation on a larger scale involving a number of schools, little research has been done concerning teacher's perception in a designated school. The research is valuable as it deepens the understanding of KM in schools regarding preparation for its implementation. These findings in turn provide insight into the further study of KM implementation in schools. In this research, some issues are still unresolved, for example: "Do subjects and gender really influence teacher's attitude to team work and technology in KM?" Different methods, such as focus group interviews and surveys, should be further used in this project. Also, further studies should be conducted in other schools with different backgrounds and characteristics in order to validate the results we found in this study, so that a more complete picture of KM implementation in a school environment can be viewed.

\section{References}

1. Bailey, C., \& Clarke, M. (2000). How do managers use knowledge about knowledge management?. Journal of Knowledge Management, 4(3), 235-243. 
2. Barron, T. (2000). A smarter Frankenstein: The merging of e-learning and knowledge management. Learning Circuits. Alexandria, VA: ASTD. Retrieved August 8, 2007, from http://www.leamingcircuits.org/aug200/barron.html.

3. Boisot, M., MacMillan, L., \& Han, K. S. (2007). Explorations in information space: Knowledge, agents, and organizations. New York: Oxford University Press.

4. Chu, K. W., Wang, M., Zhou, S., \& Yuen, A. H. K. (2009). Teacher Perception of Knowledge Management: A Case Study in a Secondary School. Session presented at the 4th International Conference on e-Learning, Toronto, Canada, 16-17.

5. Cochran-Smith, M., \& Lytle, S. L. (1999). Teacher learning in professional communities: Three knowledge -practice relationships. In P. D. Pearson \& A. IranNejad (Eds.), Reviews of research in education (pp. 251-307). Washington, DC: American Educational Research Association.

6. Davenport, T. H., \& Prusak, L. (1997). Working knowledge: How organizations manage what they know. Cambridge, MA: Harvard Business School Press.

7. Dixon, N. (2002). The neglected receiver of knowledge sharing. Ivey Business Journal, 64(4), 35-40.

8. Ge, X., Zhang, X. M., \& Wang, Q. (2006). The development of teachers specialization in the perspective of educational knowledge management. Computer Knowledge and Technology, 13(12), 227-228.

9. Kogut, B., \& Zander, U. (1996). What firms do? Coordination, identity, and learning. Organization Science, 7(5), 502-518.

10. McCampbell, A. S., Clare, L. M., \& Gitters, S. H. (1999). Knowledge management: the new challenge for the 21st century. Journal of Knowledge Management, 3(3), 172-179.

11. Nonaka, I. (1994). A dynamic theory of organizational knowledge creation. Organization Science, 5(1), 14-37.

12. Nonaka, I., \& Takeuchi, H. (1995). The knowledge-creating company: how Japanese companies create the dynamics of innovation. New York: Oxford University Press.

13. Petrides, L. A., \& Nodine, T. R. (2003). Knowledge management in education : Defining the Landscape. (Report). Half Moon Bay, CA.: Institute for the study of Knowledge Management in Education.

14. Polanyi, M. (1967). The tacit dimension. New York: Doubleday.

15. Reynolds, N., Diamantopoulos, A., \& Schlegelmilch, B. B. (1993). Pretesting in questionnaire design: A review of the literature and suggestions for further research. Journal of the Market Research Society, 35, 171-182.

16. Rodrigues, L. L. R., \& Pai, R. (2005). Preparation and validation of KM measurment instrument : an empirical study in educational and IT sectors. In S. AlHawamdeh \& M. International Conference on Knowledge (Eds.), Knowledge management : nurturing culture, innovation and technology : proceedings of the 2005 International Conference on Knowledge Management, North Carolina, USA, 27-28 October 2005 (pp. 582-593). Singapore ; Hackensack, N.J.: World Scientific..

17. Wang, J. X., \& Jia, C. J. (2005). Education knowledge management strategies to promote teachers' professional development. Science \& Technology Progress and Policy, 22(12), 159-161. 
18. Wiig K. M. (1999). Introducing knowledge management into the enterprise. In Liebowitz J (ed.), Knowledge management handbook, CRC Press: Boca Raton, FL; pp.3.1-3.41.

19. Zhao, J. (2010). School knowledge management framework and strategies: The new perspective on teacher professional development. Computers in Human Behavior, 26(2), 168-175. 